\title{
Screening Ornamental Cherry (Prunus) Taxa for Resistance to Infection by Blumeriella jaapii
}

\author{
Yonghong Guo \\ Floral and Nursery Plants Research Unit, U.S. National Arboretum, U.S. \\ Department of Agriculture, Agricultural Research Service, 10300 Baltimore \\ Avenue, Beltsville, MD 20705
}

Matthew Kramer

Statistics Group, U.S. Department of Agriculture, Agricultural Research Service, 10300 Baltimore Avenue, Beltsville, MD 20705

\section{Margaret Pooler ${ }^{1}$}

Floral and Nursery Plants Research Unit, U.S. National Arboretum, U.S. Department of Agriculture, Agricultural Research Service, 10300 Baltimore Avenue, Beltsville, MD 20705

Additional index words. breeding, flowering cherry, germplasm evaluation, cherry leaf spot

Abstract. Ornamental flowering cherry trees are important landscape plants in the United States but are susceptible to several serious pests and disease problems. Cherry leaf spot, incited by the fungus Blumeriella jaapii, is characterized by defoliating susceptible trees in late summer, leading to weakening or even death of the tree. To identify resistant plants for use in landscape plantings and in our breeding program, we used a detached leaf assay to screen 69 diverse ornamental flowering cherry taxa for resistance to cherry leaf spot. We found clear differences in susceptibility among the accessions, with seven accessions developing essentially no symptoms at all. A variance decomposition showed that most of the variance $(59 \%)$ occurred among accessions, indicating that genotype, even more than species, determined susceptibility. The detached leaf assay used in this study is an effective method for screening large numbers of plants for relative resistance to cherry leaf spot. These methods will be particularly useful to characterize germplasm and screen hybrids in breeding and selection programs.

Ornamental flowering cherry trees (Prunus L. species) are popular plants for street, commercial, and residential landscapes. Grown primarily for their spring bloom, flowering cherries have been in the United States since the mid-1850s (Faust and Suranyi, 1997) and gained in popularity after the historic Tidal Basin cherries were planted in Washington, D.C., in 1912 (Jefferson and Fusonie, 1977). According to the 2014 United States Department of Agriculture (USDA) Census of Horticulture Specialties (USDA-NASS, 2015), flowering cherries are the second most valuable deciduous flowering trees in the United States, with a total crop value of $\$ 33.2$ million, and the fourth most commonly grown flowering deciduous trees in the United States, with nearly 1.2 million plants grown annually. According to the 2014 census, flowering cherries were sold by 912 wholesale or retail nurseries in 44 U.S. states.

For all their iconic popularity, flowering cherries are plagued by a large number of disease and pest problems incited by bacterial, viral, fungal, and insect pests, including

Received for publication 5 Oct. 2017. Accepted for publication 5 Dec. 2017.

${ }^{1}$ Corresponding author. E-mail: margaret.pooler@ ars.usda.gov. and likely most effective method for longterm disease management. Disease-resistant taxa have been found for use in sour and sweet cherry breeding programs (Stegmeir et al., 2014; Wharton et al., 2003), and detached leaf assays have been developed (Wharton et al., 2003). A field screening of six popular ornamental cultivars revealed differential resistance in those taxa as well (Joshua et al., 2017). The objectives of the present study were 2-fold: 1) to screen a large and diverse base of ornamental flowering cherry germplasm to identify the most resistant taxa for use in landscape plantings and in our breeding program, and 2) to verify that our detached leaf assay for this fungus was effective for flowering cherry taxa, where whole tree assays are often impractical.

\section{Materials and Methods}

Plant materials. Sixty-nine diverse accessions of ornamental flowering cherries were selected for testing. These plants were mature trees representing multiple accessions of species, well-known cultivars, and hybrids from the USDA-Agricultural Research Service U.S. National Arboretum (USNA) breeding program (Table 1). Three terminal leaves per tree were taken from trees growing at the USNA sites in Washington D.C., or Beltsville, MD. Leaves were sampled over a 2-week interval in late June and early July.

Fungal isolation. Blumeriella jaapii was isolated following the general approach of Proffer et al. (2006) and Wharton et al. (2003). Fungal spores were isolated from symptomatic leaves of heavily infected flowering cherry trees growing at the U.S. National Arboretum's Woody Plant Landscape Germplasm Repository in Beltsville, MD. Leaves were collected in late Sept. 2016 and stored briefly at $4{ }^{\circ} \mathrm{C}$ until use. To enhance sporulation, the leaves were washed with sterile water, placed in sealed plastic bags, and left at room temperature (20 to $25^{\circ} \mathrm{C}$ ) for $3-5 \mathrm{~d}$. The conidia from a single lesion with sporulating acervulus were streaked on to modified malt extract agar (MMEA) plates $(2 \%$ malt extract, $0.1 \%$ yeast extract, $2 \%$ agar) supplemented with streptomycin and neomycin at $20 \mu \mathrm{g} \cdot \mathrm{mL}^{-1}$ each. The streaked plates were sealed with parafilm and incubated at $23{ }^{\circ} \mathrm{C}$ until visible colonies appeared in $\approx 14 \mathrm{~d}$. Single colonies were transferred to fresh MMEA plates without antibiotics and grown at $23{ }^{\circ} \mathrm{C}$ for $14 \mathrm{~d}$ in the dark. When the colonies reached $10 \mathrm{~mm}$ in diameter, the plates were placed in the refrigerator and stored at $4{ }^{\circ} \mathrm{C}$ until use. To subculture the isolates, the colonies were ground into pieces with a sterile spatula in $100 \mu \mathrm{L}$ sterile distilled water. The resultant suspension was spread evenly over MMEA plates and incubated at $23{ }^{\circ} \mathrm{C}$ in dark. To produce spores, all isolates were subcultured on potato dextrose agar plates under fluorescent light at $23{ }^{\circ} \mathrm{C}$.

Fungal identification. Fungal isolates were verified as $B$. jaapii using polymerase 
chain reaction (PCR) and conidia morphological comparison with the isolate ENT6-14 kindly provided by Dr. George Sundin (Michigan State University, East Lansing,
MI). DNA was extracted from mycelium of the fungal isolates and PCR was performed using the primer pair $\mathrm{Bj}-\mathrm{F}$ and $\mathrm{Bj}-\mathrm{R}$ according to Proffer et al. (2006).
Inoculation. Three colonies, each $\approx 10 \mathrm{~mm}$ in diameter, were homogenized with $1 \mathrm{~mL}$ sterile distilled water with a mortar and pestle. The resultant mycelium solution

Table 1. Ornamental Prunus taxa used in this study.

\begin{tabular}{|c|c|c|}
\hline Prunus taxon ${ }^{\mathrm{z}}$ & Number tested & Accessions tested ${ }^{y}$ \\
\hline \multicolumn{3}{|l|}{ Species } \\
\hline Prunus campanulata Maxim. & 5 & 58775, 38415, 58778, 58776, and 69013 ('Abigail Adams') \\
\hline Prunus cerasoides D. Don & 1 & $50682-001$ \\
\hline Prunus grayana Maxim. & 1 & 43056 \\
\hline Prunus incisa Thunb. & 7 & $45937,50694,58815,50698,58817,50685$, and 47106 ('February Pink') \\
\hline Prunus maackii Rupr. & 3 & $68773-2,68773-1$, and 70769 \\
\hline Prunus nipponica var. kurilensis E.H. Wilson & 2 & $44107-\mathrm{J}$ and 58874 \\
\hline Prunus padus L. & 2 & 62808 and 37040 \\
\hline Prunus salicina Lindl. & 1 & 67714 \\
\hline Prunus sargentii Rehder & 5 & 58891, 58892, 29928-J, 58893, and 74573-J ('Princeton Snow Cloud') \\
\hline Prunus serrulata var. pubescens Nakai & 1 & 1198 ('Fudanzakura') \\
\hline Prunus subhirtella Miq. & 5 & $50739,61383-001,61383,74569$ ('Autum. Rosea'), and 3695-J ('Pendula') \\
\hline Prunus takesimensis Nakai & 6 & $58809,58802-003,58808.01-01,58799-\mathrm{J}, 58807$, and 58810-002 \\
\hline Prunus 'Accolade' & 1 & 69777 \\
\hline Prunus 'Dream Catcher' & 1 & 61050-CJ \\
\hline Prunus 'Helen Taft' & 1 & $61128-\mathrm{T}$ \\
\hline Prunus 'Snofozam' & 1 & 74571 (Snow Fountains ${ }^{\circledR}$ ) \\
\hline Prunus 'Snow Goose' & 1 & 74575 \\
\hline Prunus $\times$ hillieri 'Spire' & 1 & 78995 \\
\hline Prunus $\times$ incam 'First Lady' & 1 & $61051-\mathrm{T}$ \\
\hline \multicolumn{3}{|l|}{ Hybrids } \\
\hline Prunus hybrid 5118 & 1 & 63464 (P. incisa $\times$ Prunus 'Kursar') \\
\hline Prunus hybrid 5120 & 1 & $63480(P$. subhirtella $\times P$. campanulata $)$ \\
\hline Prunus hybrid 5131 & 1 & 82087-01 [(Prunus 'Umineko' $\times P$. incisa $) \times(P$. subhirtella $\times P$. campanulata $)]$ \\
\hline Prunus hybrid 58881 & 1 & 58881 (P. nipponica var. kurilensis $\times P$. sargentii) \\
\hline
\end{tabular}

${ }^{\mathrm{z}}$ Species designations and authorities follow taxonomy from the United States Department of Agriculture-Agricultural Research Service Germplasm Resources Information Network (https://npgsweb.ars-grin.gov/gringlobal/taxon/taxonomyquery.aspx).

${ }^{\mathrm{y}}$ Numbers are National Arboretum accession numbers.

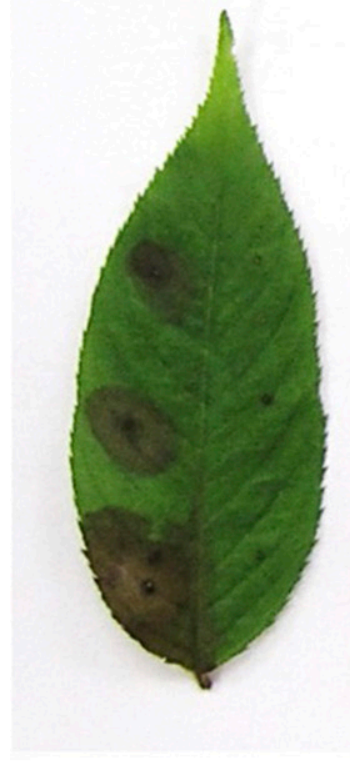

NA 3695-J

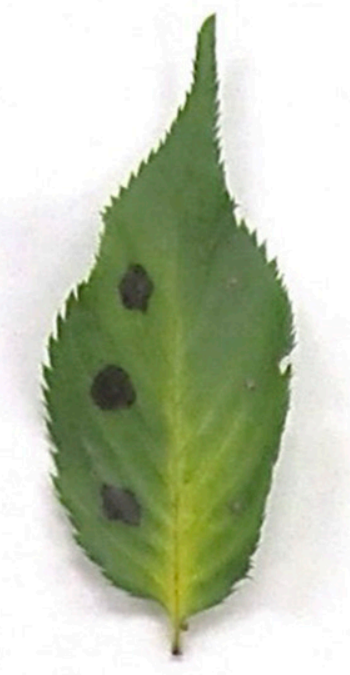

NA 61383

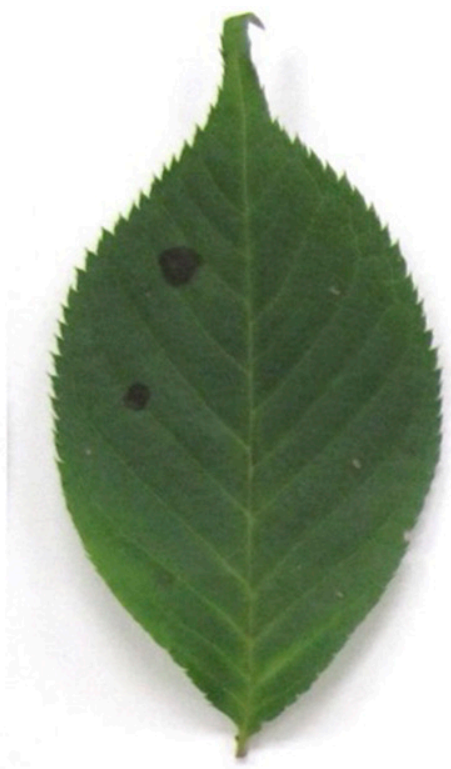

NA 74573

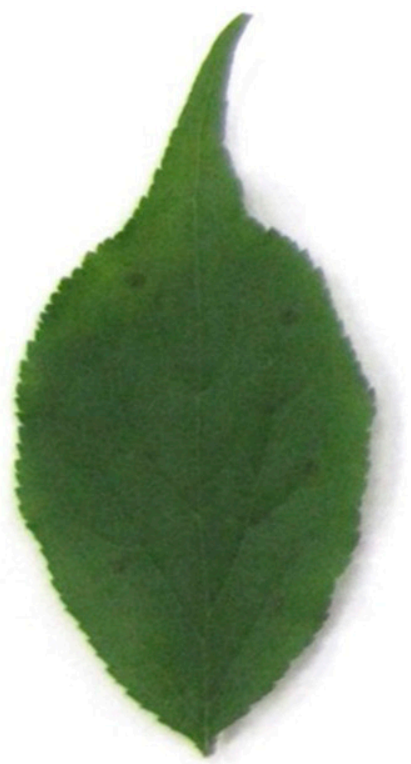

NA 64974

Fig. 1. Prunus detached leaf assay showing examples of different responses of taxa to inoculation with Blumeriella jaapii (left half of leaves) and water inoculation (right half of leaves). Taxa shown are most susceptible (on the left) to least susceptible (on the right). 
was filtered through three layers of cheesecloth and used as inoculum. Three terminal leaves were collected from mature trees in June or July. The leaves were surface sterilized by immersion in $70 \%$ alcohol for $5-10 \mathrm{~s}$, then rinsed three times with sterile distilled water. Extra water was blotted off with sterile paper towels. Each leaf was wounded in six places on the top (adaxial) surface (three on each leaf half) by gentle pressure with a $200-\mu \mathrm{L}$ pipette tip, resulting in a 0.1-cm-diameter wound. The three wounded spots on one half of the leaf were then inoculated with $2 \mu \mathrm{L}$ of mycelium and the wounded spots on the other half of the leaf were inoculated with $2 \mu \mathrm{L}$ of water as a control (Fig. 1). The inoculated leaves were placed faceup on two layers of moistened filter paper in $100 \times 10$-mm polystyrene petri dishes. The petri dishes were incubated in a growth chamber at $23{ }^{\circ} \mathrm{C}$ with

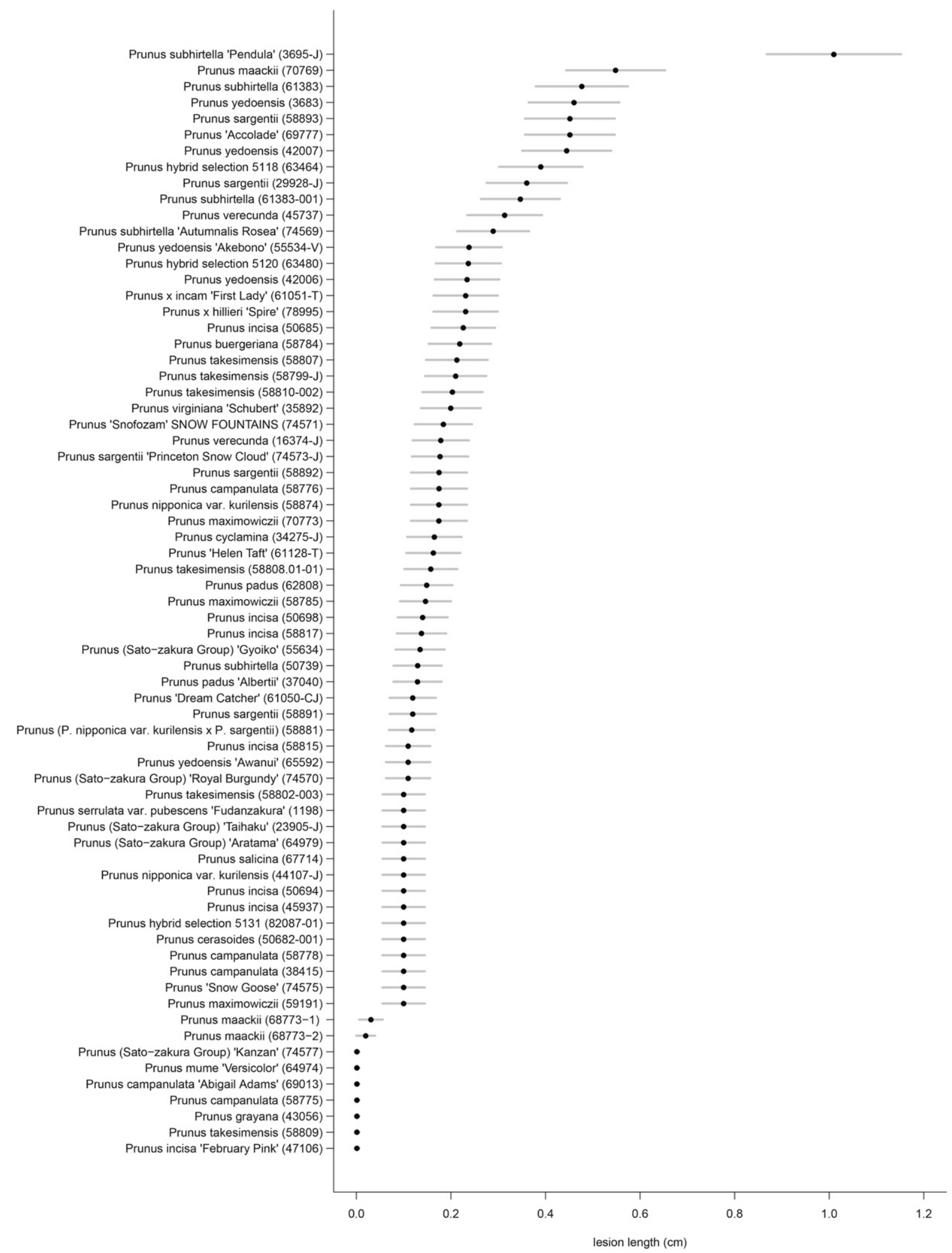

Fig. 2. Average lesion length (with 95\% confidence intervals) on 69 ornamental Prunus accessions inoculated with Blumeriella jaapii. 
a 12-h photoperiod. After $7 \mathrm{~d}$, the lesion size was measured to the nearest $\mathrm{mm}$ and recorded.

Data analysis. Preliminary analysis of the lesion data suggested that a transformation was needed to remove the dependency of the variance on the mean, as is common for data with a hard lower limit of zero. The square root transformation was used, which yielded good separation of accessions and near normal distributed residuals. A variance decomposition of the transformed lesion data were conducted using the lme4 package (Bates et al., 2015) in $\mathrm{R}$ ( $\mathrm{R}$ Core Team, 2017). Based on these results, we decided to estimate means and their 95\% confidence intervals of accessions, rather than species, as detailed in the following paragraphs. Means and their 95\% confidence intervals were back-transformed to the original scale using the delta method in the lsmeans package (Lenth, 2016) in R.

\section{Results and Discussion}

We found clear differences in susceptibility among the accessions, with seven accessions developing no lesions at all (Fig. 2). A variance decomposition indicated very little variation from leaf to leaf $(3 \%$ of the total variance), indicating that replications within an accession produced uniform measurements. Most of the observed variance $(59 \%)$ occurred among accessions, indicating that genotype, even more than species (14\%), determined susceptibility in our study. The remaining $24 \%$ of the variation is attributed to spot-to-spot variability within a leaf (i.e., residual variance), which could be due to anatomical difference across the leaf such as stomatal density or differences in wounding or inoculation effectiveness. Some species were relatively uniform among tested accessions in their susceptibility. For example, four of the five accessions of Prunus yedoensis and Prunus sargentii developed larger lesions, whereas four of the five Prunus campanulata accessions were relatively resistant. Other species, however, varied substantially in their response to inoculation among accessions. For example, accessions of Prunus maackii (three tested), Prunus takesimensis (six tested), and Prunus incisa (seven tested) were among the most susceptible and the most resistant plants tested. Our results on host resistance among cultivars is in agreement with those of Joshua et al. (2017), who tested six ornamental Prunus cultivars and found that Yoshino ( $P$. yedoensis) was among the most susceptible and Kwanzan (Kanzan in our study) was the most resistant. Our study broadens the scope of this previous work on ornamental cherries to provide resistance/susceptibility data for more taxa that are important in landscapes, the nursery trade, and our breeding program.

Based on genetic studies of resistance to B. jaapii in other Prunus species, the profound effect of genotype on disease resistance in ornamental Prunus taxa (even within a species) is not unexpected. A source of resistance to B. jaapii for use in sweet and sour cherry breeding programs has been found in the diploid species $P$. canescens and also in Prunus fruticosa from Russia (Wharton et al., 2003). Studies in $P$. avium by Diaz et al. (2007) indicate that resistance appears to exhibit high broad-sense heritability, and Stegmeir et al. (2014) explained the inheritance of resistance from $P$. canescens using a two-gene model and identified a quantitative trait locus associated with resistance from this source. These results readily explain the differences in resistance seen between seedlings of the same species in $P$. avium (Diaz et al., 2007) and in P. fruticosa (Wharton et al., 2003), as well as the difference among accessions of the same species observed in our study. A large broad-sense variability means that much of the variation seen in susceptibility is due to genetic variation. The variance decomposition was useful to identify what level of taxon is needed for screening and breeding (individual accessions rather than species) against this fungal pathogen.

There are many methods available to determine relative disease resistance in plants. Although inoculating multiple replications of whole plants works well for annual herbaceous crops, this technique is generally not feasible for tree species, where long generation times, variable environments and physiological states among plants, and large space requirements can confound results. Wharton et al. (2003) found that using a detached leaf assay to screen sour cherries for resistance to B. jaapii gave comparable results to whole plant inoculations. Similarly, our results are in agreement with those of Joshua et al. (2017) who tested some of the same taxa that we tested, but used whole plant evaluations. We conclude, therefore, that our detached leaf assay is an effective method for screening large numbers of plants for relative resistance to CLS. These methods will be particularly useful to characterize germplasm and screen hybrids in breeding and selection programs.

\section{Literature Cited}

Bates, D., M. Maechler, B. Bolker, and S. Walker. 2015. Fitting linear mixed-effects models using lme4. J. Stat. Softw. 67:1-48.

Diaz, R., R. Zas, and J. Fernandez-Lopez. 2007. Genetic variation of Prunus avium in susceptibility to cherry leaf spot (Blumeriella jaapii) in spatially heterogeneous infected seed orchards. Ann. For. Sci. 64:21-30.
Faust, M. and D. Suranyi. 1997. Origin and dissemination of cherry, p. 263-317. In: J. Janick (ed.). Horticultural reviews. Wiley, Hoboken, NJ.

Gruber, B.R., E.L. Kruger, and P.S. McManus. 2012. Effects of cherry leaf spot on photosynthesis in tart cherry 'Montmorency' foliage. Phytopathology 102:656-661.

Holb, I.J. 2013. Effect of sanitation treatments on leaf litter density and leaf spot incidence in integrated and organic sour cherry orchards. Plant Dis. 97:891-896.

Jefferson, R.M. and A.E. Fusonie. 1977. The Japanese flowering cherry trees of Washington, D.C. U.S. Dept. Agr., Natl. Arboretum Contrib. No. 4.

Jones, A.L., G.R. Ehret, and S.M. Garcia. 1993. Control of cherry leaf spot and powdery mildew on sour cherry with alternate-side applications of fenarimol, myclobutanil, and tebuconazole. Plant Dis. 77:703-706.

Joshua, J. and M.T. Mmbaga. 2015. Perpetuation of cherry leaf spot disease in ornamental cherry. J. Phytopathol. 163:194-201.

Joshua, J., M.T. Mmbaga, and L.A. Mackasmiel. 2017. Cherry leaf spot disease management in ornamental cherries in mid-Tennessee. Can. J. Plant Sci. 97:110-118.

Lenth, R.V. 2016. Least-squares means: The R package 1smeans. J. Stat. Softw. 69:1-33.

Ma, Z., T.J. Proffer, J.L. Jacobs, and G.W. Sundin. 2006. Overexpression of the 14a-demethylase target gene (CYP51) mediates fungicide resistance in Blumeriella jaapii. Appl. Environ. Microbiol. 72:2581-2585.

McManus, P.S., T.J. Proffer, R. Berardi, B.R. Guber, J.E. Nugent, G.R. Ehret, Z. Ma, and G.W. Sundin. 2007. Integration of copperbased and reduced-risk fungicides for control of Blumeriella jaapii on sour cherry. Plant Dis. 91:294-300.

Proffer, T.J., R. Berardi, Z. Ma, J.E. Nugent, G.R. Ehret, P.S. McManus, A.L. Jones, and G.W Sundin. 2006. Occurrence, distribution, and polymerase chain reaction-based detection of resistance to sterol demethylation inhibitor fungicides in populations of Blumeriella jaapii in Michigan. Phytopathology 96:709-717.

Pscheidt, J.W. and R.S. Byther. 2001. Prunus diseases, p. 317-325. In: R.K. Jones and D.M. Benson (eds.). Diseases of woody ornamentals and trees in nurseries. APS Press, St. Paul, MN

R Core Team. 2017. R: A language and environment for statistical computing. R Foundation for Statistical Computing, Vienna, Austria. 23 Jan. 2018. <https://www.R-project.org/>.

Stanosz, G.R. 1992. Effect of cherry leaf spot on nursery black cherry seedlings and potential benefits from control. Plant Dis. 76:602-604.

Stegmeir, T., M. Schuster, A. Sebolt, U. Rosyara, G.W. Sundin, and A. Iezzoni. 2014. Cherry leaf spot resistance in cherry (Prunus) is associated with a quantitative trait locus on linkage group 4 inherited from $P$. canescens. Mol. Breeding 34:927-935.

USDA-NASS. 2015. 2014 census of horticultural specialties. 23 Jan. 2018. $<\mathrm{https}$ ://www.agcensus. usda.gov/Publications/2012/Online_Resources/ Census_of_Horticulture_Specialties/HORTIC pdf $>$.

Wharton, P.S., A. Iezzoni, and A.L. Jones. 2003. Screening cherry germplasm for resistance to leaf spot. Plant Dis. 87:471-477. 